\title{
Salivary cortisol and the diagnosis of Cushing's syndrome: a coming of age
}

\author{
Hershel Raff
}

Published online: 29 March 2012

(C) Springer Science+Business Media, LLC 2012

The diagnosis and differential diagnosis of endogenous hypercortisolism - the Cushing's syndrome-is one of the most challenging problems in clinical endocrinology. Screening the large proportion of the population with one or more of the signs and symptoms of Cushing's syndrome requires a simple, inexpensive, and reliable test [1]. As has been demonstrated in multiple studies, the measurement of an increased late-night salivary cortisol (LNSC) clearly fits the bill because of its high sensitivity and specificity for the diagnosis of Cushing's syndrome [2]. The theory behind the test and its execution has been exhaustively reviewed and is now widely accepted [3, 4].

The study by Belaya et al. [5] appearing in this journal confirms prior studies that the measurement of LNSC can be performed by a widely available platform immunoassay. Considering the simplicity of obtaining an LNSC sample and the availability of the measurement by platform immunoassay, there should be no barrier to any clinician obtaining this screening test even with a modest degree of suspicion of Cushing's syndrome.

The study of Belaya et al. brings up a few caveats and issues that should be considered when doing the test.

(1) When we first started doing LNSC, we obtained two LNSC samples 24 or $48 \mathrm{~h}$ apart [6]. This was based on the conjecture that there would be significant

H. Raff $(\bowtie)$

Endocrine Research Laboratory, Aurora St. Luke's Medical Center, Aurora St. Luke's Physician's Office Bldg, 2801 W KK River Pky Suite 245, Milwaukee, WI 53215, USA

e-mail: hraff@mcw.edu

H. Raff

Departments of Medicine, Surgery, and Physiology, Medical College of Wisconsin, Milwaukee, WI 53215, USA within-subject variability in the LNSC results. This has led to some discordant results and confusion as to what to do next. The study of Belaya et al. suggests that one correctly collected LNSC sample is adequate. Conversely, a study by Carrasco et al. [7] also published in this journal demonstrated (using an automated platform immunoassay), that the diagnostic accuracy of LNSC testing for the diagnosis of Cushing's syndrome is improved by obtaining two samples. Therefore, we continue to recommend obtaining two LNSC samples. In addition to the potential for improvement in diagnostic accuracy, there is a logistical reason to obtain two LNSC samples. It is not uncommon for one of the samples to have insufficient quantity of saliva for analysis even with our extraordinarily sensitive ELISA that requires only $25 \mu \mathrm{L}$ of saliva per well [8]. In fact, one piece of information apparently not included in Belaya et al. [5] or Carrasco et al. [7] is the volume of saliva necessary for the automated immunoassay, although a study using a similar automated immunoassay stated that only $20 \mu \mathrm{L}$ of saliva is necessary [9]. Regardless, since the saliva sampling is done at home and we receive samples from across the US, we find it prudent to obtain two samples in case one has inadequate volume or some other problem with sample integrity.

(2) Belaya et al. found a lower specificity for the diagnosis of Cushing's syndrome using LNSC measurement when an obese group in whom Cushing's syndrome had been discounted was used as the comparator rather than a non-obese healthy group of controls. As admitted in the paper, it is possible that some of the subjects with presumed constitutional obesity actually had subclinical Cushing's syndrome 
rather than "functional hypercortisolism (due to obesity)". Since the other confirmatory screening tests for Cushing's syndrome can also be misleading, this issue cannot be resolved simply. Since the overnight dexamethasone suppression test combined with LNSC improved the overall specificity, as demonstrated previously [10], the authors may be correct.

(3) One problem not mentioned by Belaya et al. [5] or Carrasco et al. [7] is the potential for contamination of the saliva sample with cross-reacting topical corticosteroids if and when the sampling is done by the subject at home [11]. It may be that over-thecounter hydrocortisone creams and ointments (containing authentic cortisol) are not widely available or used in Russia or Chile. Regardless, this is a significant issue in the United States that can be resolved by demonstrating a lack of increased salivary cortisone measured by LC-MS/MS [12].

Belaya et al. [5] are blessed with a very high number of patients with Cushing's syndrome to evaluate. They are apparently a regional or national referral center such that they discovered 45 patients with proven Cushing's syndrome out of 123 patients referred for the suspicion of Cushing's syndrome! This was accomplished during only 1 year of referrals! It would be wonderful if, in the United States, all patients with at least a moderate suspicion of a relatively rare disease like Cushing's syndrome could be referred to a regional center with vast experience. This would not only allow scientific studies with improved power, but would also very likely improve the diagnosis and treatment of individuals with this protean disease. The clinical evaluation of subtle Cushing's syndrome is an art that requires significant experience and expertise. As my clinical colleague, James Findling, has stated [13],

If you have never missed the diagnosis of Cushing's syndrome or been humbled by trying to establish its cause, then you should refer your patients who have suspected hypercortisolism to someone who has.

The widespread use of LNSC to screen for Cushing's syndrome will continue to improve the detection of affected patients leading to referral to the appropriate centers for the confirmation of the diagnosis as well as the appropriate differential diagnosis and treatment.

\section{References}

1. J.W. Findling, H. Raff, Screening and diagnosis of Cushing's syndrome. Endocrinol. Metab. Clin. North Am. 34, 385-402 (2005)

2. T. Carroll, H. Raff, J.W. Findling, Late-night salivary cortisol for the diagnosis of Cushing's syndrome: a meta-analysis. Endocr. Pract. 15, 335-342 (2009)

3. H. Raff, Utility of salivary cortisol measurements in Cushing's syndrome and adrenal insufficiency. J. Clin. Endocrinol. Metab. 94, 3647-3655 (2009)

4. L.K. Nieman, B.M. Biller, J.W. Findling, J. Newell-Price, M.O. Savage, P.M. Stewart, V.M. Montori, The diagnosis of Cushing's syndrome: an Endocrine Society Clinical Practice Guideline. J. Clin. Endocrinol. Metab. 93, 1526-1540 (2008)

5. Z.E. Belaya, A.V. Iljin, G.A. Melnichenko, L.Y. Rozhinskaya, N.V. Dragunova, L.K. Dzeranova, S.A. Butrova, E.A. Troshina, I.I. Dedov, Diagnostic performance of late-night salivary cortisol measured by automated electrochemiluminescence immunoassay in obese and overweight patients referred to exclude Cushing's syndrome. Endocrine. (2012). doi:10.1007/s12020-012-9658-3

6. H. Raff, J.L. Raff, J.W. Findling, Late-night salivary cortisol as a screening test for Cushing's syndrome. J. Clin. Endocrinol. Metab. 83, 2681-2686 (1998)

7. C.A. Carrasco, M. Garcia, M. Goycoolea, J. Cerda, J. Bertherat, O. Padilla, D. Meza, N. Wohllk, T. Quiroga, Reproducibility and performance of one or two samples of salivary cortisol in the diagnosis of Cushing's syndrome using an automated immunoassay system. Endocrine (2012). doi: 10.1007/s12020-012-9597-z

8. H. Raff, P.J. Homar, D.P. Skoner, A new enzyme immunoassay for salivary cortisol. Clin. Chem. 49, 203-204 (2003)

9. M. Vogeser, J. Durner, E. Seliger, C. Auernhammer, Measurement of late-night salivary cortisol with an automated immunoassay system. Clin. Chem. Lab. Med. 44, 1441-1445 (2006)

10. M. Castro, P.C. Elias, A.R. Quidute, F.P. Halah, A.C. Moreira, Out-patient screening for Cushing's syndrome: the sensitivity of the combination of circadian rhythm and overnight dexamethasone suppression salivary cortisol tests. J. Clin. Endocrinol. Metab. 84, 878-882 (1999)

11. H. Raff, Cushing's syndrome: diagnosis and surveillance using salivary cortisol. Pituitary 15, 64-70 (2012)

12. H. Raff, R.J. Singh, Measurement of late night salivary cortisol and cortisone by liquid chromatography—-tandem mass spectrometry to assess pre-analytical sample contamination with topical hydrocortisone. Clin. Chem. (2012). doi:10.1373/clinchem.2012. 182717

13. J.W. Findling, H. Raff, Preface-Cushing's syndrome. Endocrinol. Metab. Clin. North Am. 34, xiii-iv (2005) 